\title{
El Mole de Caderas. \\ Platillo tradicional del Baile de Matanza de México
}

\author{
Fernando Hernández García* \\ Enrique de Jesús Garduño Gómez**
}

DOI: https://doi.org/10.33571/revinterseccion.v2n4a7

\section{Resumen}

En México, el 20 de octubre de cada año se realiza el Baile de la Matanza, la historia de esta festividad data del siglo XVII la cual es producto del mestizaje entre lo hispánico y lo mesoamericano. Cuando se incorpora el ganado caprino a la Nueva España se presenta un proceso de sincretización dentro de la gastronomía, surgiendo platillos que aprovecharon de la manera más amplia los derivados de ese ganado. Así, durante el siglo XVIII, el mole de caderas ganó protagonismo en la gastronomía común entre Tehuacán - Estado de Puebla y Huajuapan de León - Estado de Oaxaca. En este artículo se contextualiza la tradición gastronómica de ese platillo mexicano.

Palabras clave: Mole de cadera; gastronomía; México; Baile de Matanza, platillos regionales.

Recibido. Octubre 23, 2020

Aceptado. Noviembre 12,2020

\footnotetext{
*Responsable de Laboratorio de Gastronomía, Eventos y Vinculación. Universidad del Valle de Puebla, Plantel Tehuacán. Orcid: https://orcid. org/0000-0001-6824-1917 ;e-mail: coord.lab.vin.eve@uvp.mx

**Responsable del área de Investigación. Universidad del Valle de Puebla, Plantel Tehuacán. Orcid: https://orcid.org/0000-0001-5223-0471
} 


\title{
Mole de Caderas.
}

\section{Traditional dish of the Matanza Dance of Mexico.}

\author{
Fernando Hernández García* \\ Enrique de Jesús Garduño Gómez**
}

DOI: https://doi.org/10.33571/revinterseccion.v2n4a7

\section{Abstract}

Baile de la Matanza takes place in Mexico, in every October 20, the history of this festivity dates back to the XVII century, it is a product of the mixture between the Hispanic and Mesoamerican. It arises from the exploitation of goat cattle introduced in the American continent during the centuries of the Colony. When goats were incorporated into the New Spain, a process of mixture started within the gastronomy, emerging dishes that took advantage in the widest way of livestock derivatives. Therefore, during the 18th century, mole de caderas gained prominence in the common gastronomy between Tehuacán - State of Puebla and Huajuapan de León - State of Oaxaca. This article contextualizes the gastronomic tradition of such Mexican dish.

Key words: Mole de cadera; gastronomy; Mexico; Baile de Matanza, regional dishes.

Recibido. October 23, 2020

Aceptado. November 12,2020

* Responsible for Gastronomy, Events and Liaison Laboratory. Universidad del Valle de Puebla, Plantel Tehuacán. Orcid: https://orcid.org/0000-00016824-1917 ; e-mail: coord.lab.vin.eve@uvp.mx

** Responsible for the Research Area. Universidad del Valle de Puebla, Plantel Tehuacán. Orcid: https://orcid.org/0000-0001-5223-0471 


\section{Mole de Caderas. \\ Prato Tradicional da Dança da Matança de México}

Fernando Hernández García*

Enrique de Jesús Garduño Gómez**

DOI: https://doi.org/10.33571/revinterseccion.v2n4a7

\section{Resumo}

No México, o 20 de Outubro de cada ano tem lugar a Dança do Abate (Baile de la Matanza), a história desta festa remonta ao século XVII, que é o produto da mistura entre as culturas hispânicas e mesoamericanas. Quando as cabras foram incorporadas na Nova Espanha, teve lugar um processo de sincretização dentro da gastronomia, dando origem a pratos que aproveitavam da forma mais ampla os derivados desse gado. Assim, durante o século XVIII, a Dança do Abate ganhou proeminência na gastronomia comum entre Tehuacán - Estado de Puebla e Huajuapan de León - Estado de Oaxaca. Este artigo contextualiza a tradição gastronómica deste prato mexicano.

Palavras-chaves: Mole de cadera; gastronomia; México; Baile de Matanza, pratos regionais.

Recebido. Outubro 23, 2020

Aceitado. Novembro 12, 2020

*Responsável pelo Laboratório de Gastronomia, Eventos e Ligação. Universidade del Valle de Puebla, Tehuacan Campus. Orcid: https:// orcid.org/0000-0001-6824-1917; e-mail: coord.lab.vin.eve@uvp.mx

**Responsável pela Área de Investigação. Universidade del Valle de Puebla, Tehuacan Campus. Orcid: https://orcid.org/0000-0001-5223-0471 


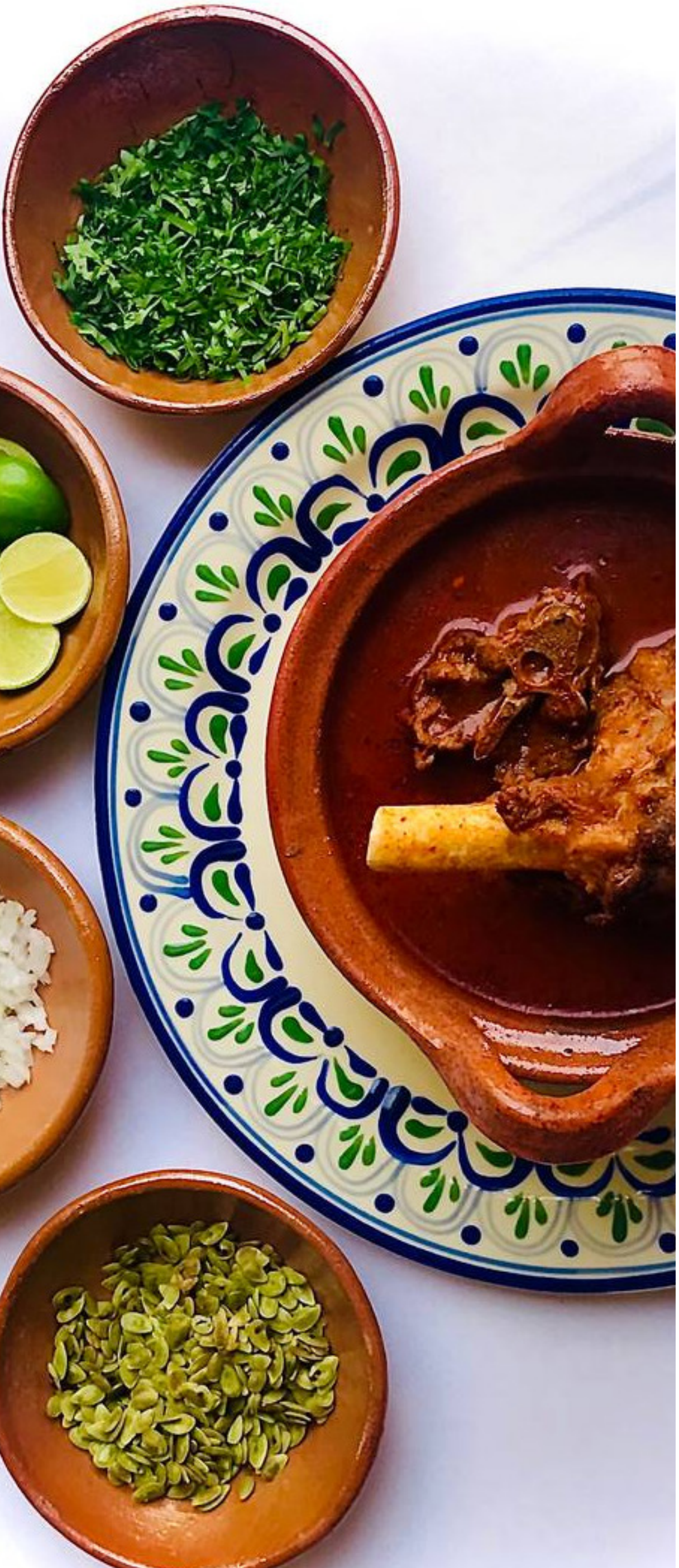

a gastronomía mexicana
es muy valorada a nive
mundial por su riqueza cultural e histórica. Cuenta con variedad de platillos; en todo el territorio es posible encontrar manifestaciones distintas de un mismo platillo, uno de estos es el mole de cadera.

Los orígenes mutidiversos de la cocina de este país se ha extendido por las cinco regiones del mundo, deleitando paladares en todos los países y a todos los niveles sociales, lo mismo que incorporando las diferentes tipologías de materias primas que (en muchas de las ocasiones) provienen de territorios lejanos, ya sea por historia o por tradición comercial.

En México, la tradición gastronómica se encuentra representada en platillos típicos que deleitan incluso a los paladares más exigentes. Originados en eventos sociales y culturales de gran pompa o importancia para la comunidad, esas preparaciones se han convertido en el elemento principal de convites, festividades o conmemoraciones para el disfrute de la convivencia. Cada platillo tiene historia y tradición, esto da cuenta del patrimonio gastronómico de cada estado o país. 


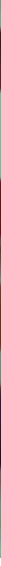

LaregiónTehuacán-Miahuatlán de México, hacompartido durante almenos doscientos años una tradición gastronómica y cultural que, hasta la fecha, se mantiene como el evento más importante entre las fiestas comunes de ambas regiones: el Festival de la Matanza. Aunque el apelativo y los rituales han sufrido algunas modificaciones y también han recibido críticas por parte de ciertos grupos, esta tradición ha logrado mantenerse en la mente y práctica de sus habitantes, considerándola fundamental para su esencia local.

El 20 de octubre de cada año se realiza el ritual conocido como Baile de la Matanza, esta festividad tiene una historia centenaria, que data del siglo XVII. Como producto del mestizaje entre lo hispánico y lo mesoamericano, todo surge de la explotación de la ganadería caprina introducida en el continente americano durante los siglos de la Colonia. Al ser incorporado el ganado caprino a la Nueva España comenzó igualmente un proceso de sincretización dentro de la gastronomía, surgiendo platillos que aprovecharon de la manera más amplia posible los derivados de ese ganado. Así, durante el siglo XVIII, nació el mole de caderas y ganó protagonismo paulatinamente en la historia común entre Tehuacán (Estado de Puebla) y Huajuapan de León (Estado de Oaxaca).

La gastronomía de la región central de México es caracterizada por la influencia, desarrollo y protagonismo de dos de los Estados más grandes del territorio: Puebla y Oaxaca. Reconocidos tanto por su riqueza cultural como por su sabor; a nivel mundial han sido embajadores de la cocina mexicana:

Diversas culturas y civilizaciones que poblaron estas regiones preservaron durante cientos de años las tradiciones de una cocina que hoy resulta fundamento de la alimentación del habitante del Anáhuac; resultado de una fusión entre los ingredientes endémicos y aquellos que llegaron de otros lugares durante la época de la Colonia.

La gastronomía poblana y oaxaqueña ha sido representativa de la cocina mexicana. Los diversos platillos que de ellas emanan han permitido visualizar la riqueza no solo de ingredientes, sino también de preparaciones y creatividad. Es fundamental recordar que sus guisos son producto de la fusión de una cantidad inimaginable de experiencias, tanto ancestrales como modernas.

El ritual étnico para la preparación del ingrediente central del Mole de Caderas, el Festival de la Matanza, integra una serie de danzas y ceremonias. La más representativa, llamada Danza de la Matanza, incluye la entonación de himnos de corte religioso (imprescindible recordar la influencia del catolicismo en la Nueva España) que, además de alabar al Creador, hace una súplica para evitar contratiempos, finalmente se sacrificar un animal ante la comunidad. 
En este proceso diversos individuos hacen parte del ritual. Los pica son los matanceros, cuadrillas integradas por habitantes de las comunidades aledañas (como San Gabriel Chilac, conocida igualmente por su exportación de ajo) quienes realizarán el procesamiento de la carne. Entre los lugares en que se conservan las características ancestrales de la pica está la Hacienda San Lorenzo, ubicada en Tehuacán, también la Hacienda Doña Carlota.

Antes de la pica, los matanceros realizan una oración para agradecer y pedir un sacrificio rápido. El primer chivo sacrificado es coronado con flor de muerto o cempasúchil, flor utilizada en las ofrendas mexicanas para adornar los altares de muertos; encienden copal como elemento ritual de comunicación entre el cielo y la tierra. El chamán (persona que tiene un contacto con la naturaleza y sus dioses) hace una oración, agradeciendo los dones recibidos. Si bien en los tiempos coloniales el cuchillo era la herramienta implementada para el sacrificio, ha sido sustituido por una pistola de aire, implemento que la Sociedad Protectora de Animales exigió a los coordinadores de la ceremonia fuera usada para evitar un espectáculo sangriento, dada la cantidad de espectadores que acuden a observar cada una de las etapas del proceso.

En tiempos pasados, unos meses antes del sacrificio, los rebaños eran pastoreados (proceso conocido como la ceba del ganado) en los territorios lindantes entre los Estados de Puebla, Guerrero y Oaxaca, zonas característicamente montañosas. Actualmente, el ganado es pastoreado, parte del año entre las costas de Guerrero y Oaxaca, y en los meses previos a la festividad son transportados al Valle de Tehuacán, en la última etapa del pastoreo se incorpora en su alimentación agua aliñada con sal proveniente de Zapotitlán Salinas (producida de manera artesanal). Esta característica alimentaria ayuda a que la carne obtenga un sabor más profundo, así como una forma tradicional para desparasitar al animal, se incluye también la ingesta de flores como chilaco, canalilli, guayabillo, cucharilla, pata de paloma y biznaga, o ramas de encino, todo ello fresco para garantizar la mejor calidad de la carne a obtener. Una circunstancia particular del cuidado por parte del pastor es la verificación del periodo de celo de las hembras, a las que se separa del rebaño con la finalidad de evitar una cruza.

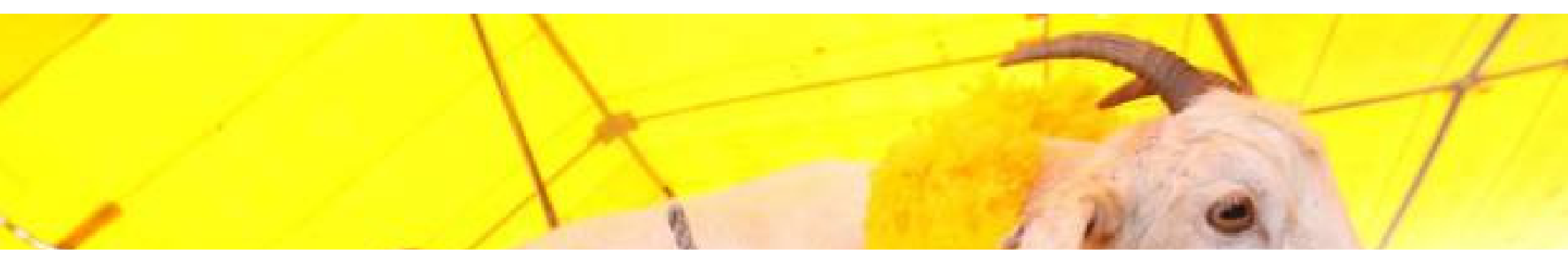




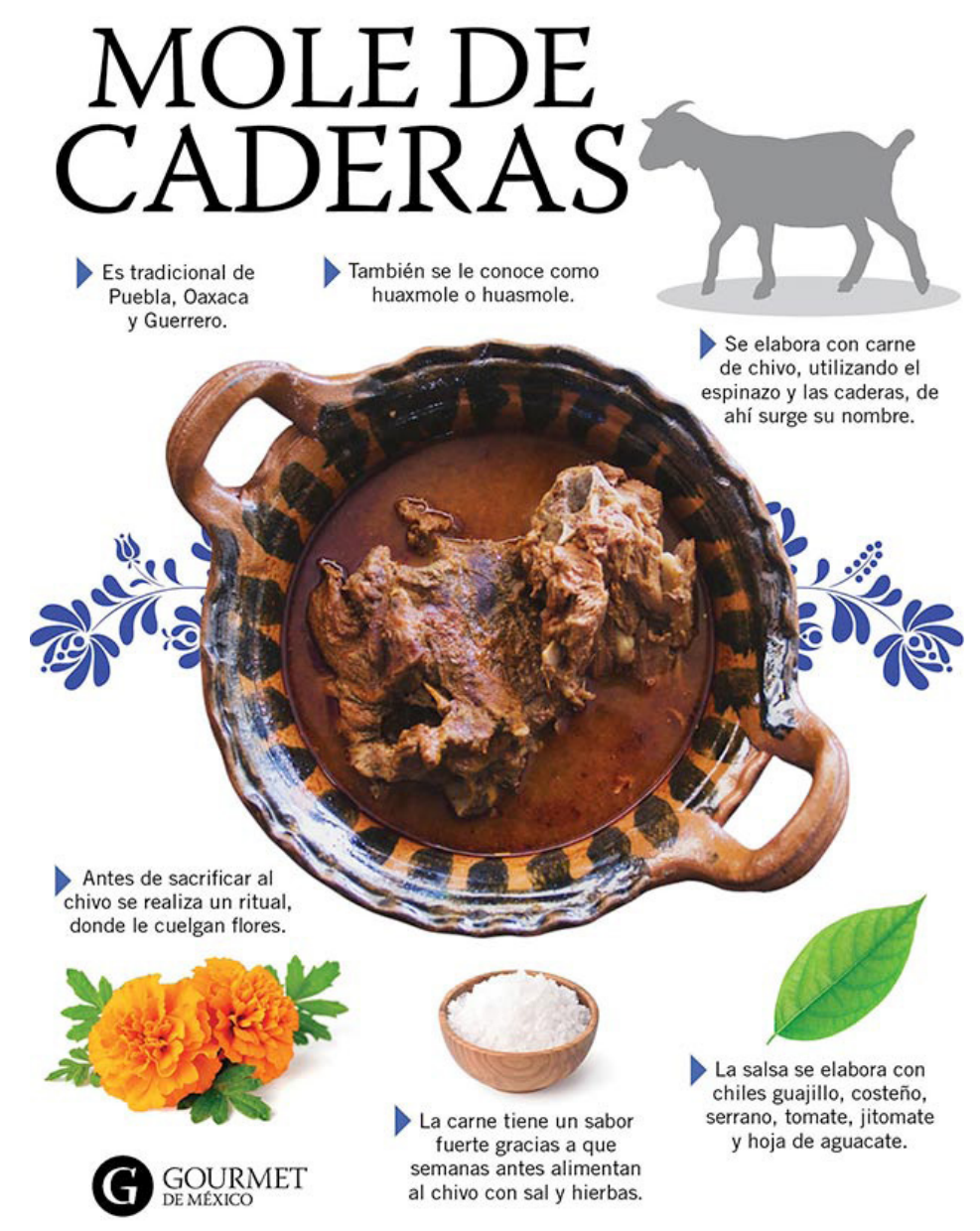

Tomada de: https://gourmetdemexico.com.mx/comida-y-cultura/mole-de-caderas-un-platillo-lleno-de-tradicion/

En Tehuacán, la cuadrilla de San Gabriel Chilac por tradición es la encargada del sacrificio del ganado. La historia oral refiere que, en tiempos de la Colonia, el pago que recibían los de la cuadrilla por su labor eran las patas de la cabra, los huesos, el espinazo y vísceras del animal, por ser considerados los despojos del animal. Cuando los dueños de las haciendas se enteran que los picadores, encargados de la matanza preparaban un caldo con eso que se consideraba desperdicio y que su sabor era muy agradable al paladar, decidieron apropiarlo y comercializarlo. El nombre que se le dio a ese platillo fue caldo de los pobres, que se preparaba con el espinazo y las caderas del chivo. Al pasar del tiempo se le dio el nombre de mole de caderas. El procesamiento actual de la carne incluye un baño en agua con sal y se deja secar, después de esta cura, que se le denomina chito, se prepara el mole de caderas. La tradición se ha preservado, siendo los huesos de la cadera del animal el ingrediente central en la preparación del platillo, que se acompaña tanto del chito como de otros ingredientes.

\section{La controversia: ¿mole o tesmole?}

El tesmole (también llamado texmole o huaxmole) es un platillo típico de la zona centro de México, cuya característica más importante es su ligereza, preparándose usualmente con carne de cerdo o res. En algunas regiones, para otorgarle espesor, recibe como añadido chochoyones u ombligos de masa de maíz, se usa comúnmente dos tipos de chile para su elaboración. 
Este mole se caracteriza por su textura espesa y el elevado número de ingredientes que se requieren para su elaboración, en algunas regiones lo llegan a aligerar con fondo blanco. A razón de esto ha surgido la controversia de si este platillo es mole de caderas o no, en tanto su consistencia no coincide con el típico mole preparado y servido en la cocina mexicana.

La gastronomía mexicana tiene un sin número de técnicas que se aplican en un solo platillo, cabe mencionar que el mole en su preparación conlleva hierbas aromáticas que transforman lo común en algo sorpréndete que cautiva los paladares más exigentes.

A raíz de esa situación, entre las comunidades de Puebla y Tehuacán existe igualmente una vieja confrontación por el origen histórico y gastronómico del platillo: ambas, en resumen, se asignan la propiedad del mole de caderas, sin poder hasta el momento constatarse el lugar exacto de su nacimiento.

\section{Receta del Mole de Caderas, según Tehuacán (Puebla)}

\section{Ingredientes:}

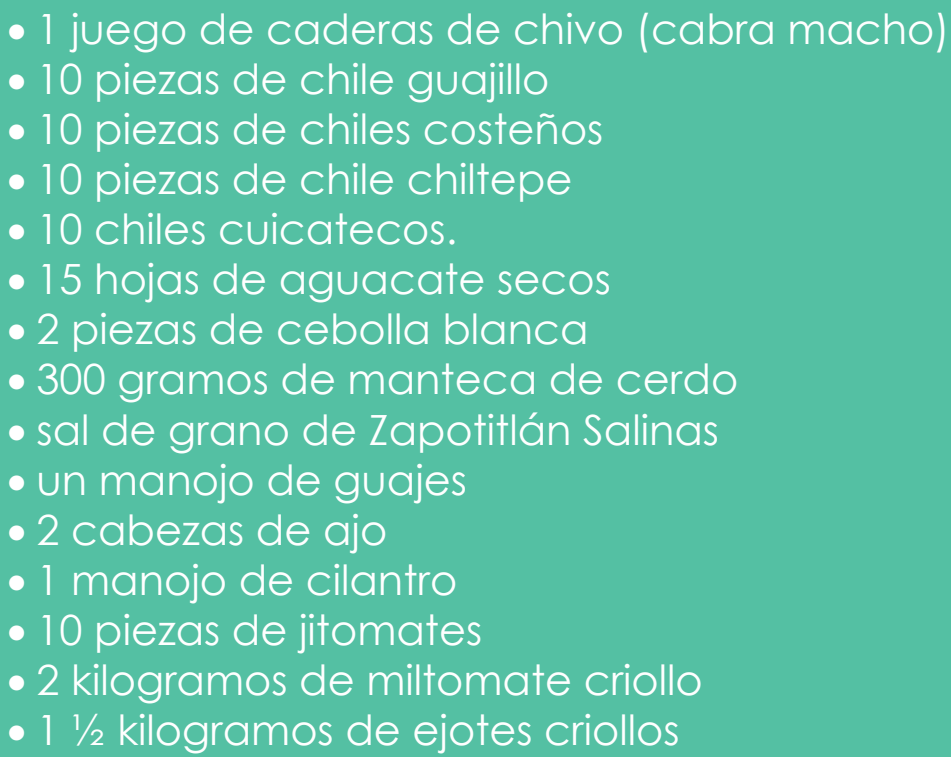

Procedimiento:

1. Las caderas del chivo se lavan con agua tibia y un cepillo de cerdas gruesa se les retiran todas las impurezas.

2. El ejote criollo debe ser cocido por separado y, posteriormente, escurrir y dar un shock térmico (agua fría o con hielo sirve para parar la cocción de un ingrediente).

3. Una olla de barro debe llenarse a la mitad con agua y se incorpora las cabezas de ajo, la cebolla blanca, las hojas de aguacate y sal de grano proveniente de Zapotitlán Salinas.

4. En otra olla de barro se lleva a hervir el tomate y el jitomate y posteriormente se provoca un shock térmico para posteriormente reservarlos.

5. Se tuestan los chiles (si no se tolera el picor se pueden limpiar y despepitar) en un comal de barro y se ponen a remojar en agua caliente para suavizarlos durante 15 minutos aproximadamente.

6. Se limpian los guajes y se asan en el comal de barro, posteriormente se muelen en el molcajete y se sofríen con manteca de cerdo, se reservan (el guaje aportará el espesor y sabor al platillo). 
7. Se muelen perfectamente los tomates y jitomates, los dientes de ajo, los chiles y se realiza una pasta. Se cuela y posteriormente se sofríe la pasta con manteca de cerdo. 8. Posteriormente se aligera la mezcla con el fondo de las caderas y se le incorpora el cilantro picado, los ejotes y se rectifica sazón. A la hora de servir se acompaña con cilantro picado, cebolla picada y limón, de guarnición arroz blanco o rojo, como maridaje son perfectos una cerveza clara o un mezcalito y como postre se ofrece el tradicional dulce de calabaza.

\section{Conclusión}

La construcción de la identidad es un proceso no solo considerado de larga duración, sino de trascendencia fundamental en la identificación de una zona, región o incluso de una nación en su totalidad. Las diversas características adquiridas, construidas - cooptadas en los procesos sociales, económicos o políticos juegan un papel preponderante en la forma que se entiende la transformación no solo de cierto tipo de acciones, sino también de los resultados que de ello se desprenda. Así, en su perspectiva fundamental, la gastronomía es uno de esos procesos relevantes en la formulación de una cultura y de la identidad de un pueblo.

América Latina goza, pues, de una gran cantidad de ejemplos que son la ventana a un pasado dicotómico, entrecruzado con diversas experiencias (tanto pacíficas como violentas) y que resulta en una gama multicolor de sabores, colores o aromas, pero, sobre todo, de la grandiosa amalgama entre lo ancestral y lo colonial, lo moderno y lo tradicional, y la forma en que esto se combina con la forma en que cada grupo humano valora, ensalza y preserva esas costumbres y tradiciones.

El mole de cadera proviene de la región Tehuacán-Miahuatlán de México, ha compartido durante al menos doscientos años una tradición gastronómica y cultural que, hasta la fecha, se mantiene como el evento más importante entre las fiestas comunes de ambas regiones: el Festival de la Matanza. Aunque el apelativo y los rituales han sufrido algunas modificaciones y también críticas por parte de ciertos grupos, esta tradición ha logrado mantenerse en la mente y práctica de sus habitantes, considerándola fundamental para su esencia local.

Para citar este artículo

Hernández. García., Garduño, E. (2021). El mole de caderas. Platillo tradicional del Baile de Matanza de México. Revista Intersección: Eventos, Turismo, Moday Gastronomía. Vol. 2, N4. Pp: 83-91; https://doi.org/10.33571/revinterseccion.v2n4a7

OJS: hithps://revistas.elpoli.edu.co/index.pho/int/issue/archive . link: httos://www.politecnicojic.edu.co/index.pho/revista-interseccion 